Gazetteer of Agricultural and Forestry Research Stations in the British Commonwealth 1952 Including a List of such Stations in the Republic of Ireland. Pp. xix +517. (Farnham Royal : Commonwealth Agricultural Bureaux, 1952.) $30 s$.

7 HE list of research workers in agriculture and forestry in the British Commonwealth, published in 1938 by the Imperial Agricultural Bureaux (as they were then), has long been a valuable reference book for all concerned. A post-war edition has been anxiously awaited and is to be greatly welcomed, particularly in the greatly extended gazetteer-form it has now taken. It will probably come as a surprise even to those engaged in work in these fields to find that particulars are included for more than a thousand research centres of various types situated within the Commonwealth.

Appraisal of the value of the changes in arrangement, and particularly in the indexes provided, will probably vary according to the special requirements and practice of the user. The gazetteer has dropped the alphabetical index of names of research workers with their countries in favour of an index to the actual research stations themselves. The former was useful in various ways and will probably be missed, while the names adopted by the research stations do not lend themselves to indexing without a lot of duplicate entries, difficult to select; the numerical device for ensuring quick recognition of the country in which the station is situated is helpful. The index for subjects of research is on a completely different basis from that of the 1938 list, and its compilation must have been a difficult and laborious task. It occupies about a hundred pages and gives references to the stations at which work is in progress on the subject in question, the serial number of the station again indicating its whereabouts; plant and animal indexes are incorporated. No attempt is made to indicate which are the major references; but this would obviously be almost impossible. Perfection is unattainable, but the outcome of a varied test on this index was quite good.

This gazetteer constitutes a much-needed and most important addition to existing facilities for intercourse and co-operation in research. H. G. C.

\section{Acoustical Designing in Architecture}

By Prof. Vern O. Knudsen and Dr. Cyril M. Harris. Pp. $x+457$. (New York: John Wiley and Sons, Inc.; London: Chapman and Hall, Ltd., 1950.) 60s. net.

JUDGING by the number of books on the acoustics 5 of buildings that have appeared in recent years, it is evident that the science of acoustics is now assuming its rightful place among the physical sciences, and this advance is to be welcomed.

The authors of the book under review are well known in the world of acoustics, and they have produced a work which is comprehensive, satisfying and very readable. It is intended mainly for architects and students of architecture, and others who probably wish for a non-mathematical yet thorough treatment of the subject; but it is safe to say that many students of physics and engineering will also find the book worth reading and investigating.

The first part of the work is devoted to a discussion of the basic principles and general procedures of design that determine the acoustical properties of all types of buildings, while subsequent chapters show how these principles and procedures can be applied to obtain the best acoustical effects. Practical applications are emphasized, and examples of good design are worked out; in addition, comprehensive tables give pertinent data on sound-absorptive materials and sound-insulative structures.

The book is well written and produced, and it should certainly serve conveniently as a handbook in the solution of most architectural acoustical problems.

\section{Sound}

By W. Hall and O. M. Matthews. Pp. viii +239. (London: Edward Arnold and Co., 1951.) $9 s$.

$7 \mathrm{HE}$ authors of this book have clearly recognized that a fuller treatment must now be accorded in schools to the subject of sound, a subject which is of ever-growing importance, and they have provided an excellent little book up to a point.

On the credit side, due emphasis is put on the importance of vibrations and waves, and the book certainly keeps abreast of modern developments, devoting one chapter to ultrasonics and another to technical applications of sound. But against these undoubted virtues, one feels that, although many facts are given and much ground covered, few topics are dealt with sufficiently fully for sixth-form pupils, and in my opinion a serious deficiency is the absence of detailed reference to the vibration of bars (of which the tuning fork is an outstanding example) and of membranes and plates.

Simple harmonic motion is dealt with in an appendix; but this might have been put in the text as a prelude to the discussion on .wave motion.

If the book is intended for sixth-form use, it is suggested that some of the elementary work at the beginning might be omitted, and it is difficult to understand why, in such a small book on sound, two pages are devoted to the Doppler effect in light.

A good selection of questions of the appropriate standard is included at the end of each chapter.

\section{T. M. YARWOOD}

\section{Proceedings of a Second Symposium on Large-}

Scale Digital Calculating Machinery

Jointly sponsored by the Navy Department, Bureau of Ordnance and Harvard University at the Computation Laboratory, 13-16 September 1949. (Annals of the Computation Laboratory of Harvard University, Vol. 26.) Pp. xxxviii + 393. (Cambridge, Mass. : Harvard University Press; London: Oxford University Press, 1951.) 52s. net.

THIS conference included papers on complete machines, machine components in development, numerical analysis, programming, and surveys of the possible applications of high-speed computing machines in physics, aeronautics, applied mechanics, and economics. Although nearly three years have elapsed since the conference took place, there is still a good deal of interest to be found in the report; for example, in the descriptions of the Harvard Mark 3 machine and the Bell Telephone Laboratories Model 6 and-in the section on programming - in D. H. Lehmer's characteristically pungent remarks on pseudo-random numbers and the use of high-speed machines for calculations connected with number theory. The paper by Harry D. Huskey on semiautomatic instructions is well worth reading in view of present-day trends in the technique of programming. 